\title{
A interdisciplinaridade e a investigação-ação na Rede Internacional de Investigação em Ensino de Ciências (RIEC)
}

\author{
Interdisciplinarity and action research in the International Science \\ Education Research Network (RIEC) \\ Interdisciplinariedad e investigación-acción en la Red Internacional de \\ Investigación en Educación Científica (RIEC)
}

\author{
Cláudia Elizandra Lemke (claudinhalemke@ @otmail.com) \\ Universidade Regional do Noroeste do Estado do Rio Grande do Sul -UNIJUI
}

Neusa Maria John Scheid (scheid.neusa@gmail.com)

Universidade Regional Integrada do Alto Uruguai e das Missões-URI

\begin{abstract}
Resumo: A RIEC é uma teia científica de interação, formação de pesquisadores, compartilhamento e produção de pesquisas de Pós-Graduação com temáticas relacionadas ao Ensino de Ciências (EC). A interdisciplinaridade, como um desafio no EC, apresenta-se como uma possibilidade de ampliar os conhecimentos, promover diálogos, e parcerias por meio da interlocução com as outras áreas. Com isso, a presente pesquisa documental por meio da revisão integrativa, investiga os periódicos das instituições vinculadas a RIEC procurando responder quantos estudos/práticas interdisciplinares estão presentes nas seções de relatos de experiências/práticas pedagógicas nesses periódicos e quais desses relatos utilizaram a metodologia da investigação-ação e/ou pesquisa-ação para realizar reflexões sobre as ações docentes. $\mathrm{O}$ descritor "interdisciplinar" foi aplicado em conjunto com os critérios de inclusão do estudo. Encontramos 21 relatos/práticas interdisciplinares, distribuídos entre o período de 2011 a 2020 examinados pela análise de conteúdo, em que 15 relatos recorreram a metodologia da investigação-ação/pesquisa-ação para refletir sobre a atuação docente nos relatos de experiência, com sua maioria realizados com o uso dos diários de bordo como instrumento de auxílio da reflexão profissional docente. Portanto, por meio dessa investigação ressaltamos a importância da RIEC como forma de contribuição da divulgação da temática da interdisciplinaridade no EC.
\end{abstract}

Palavras-chave: Rede internacional; Relato de experiência; Prática pedagógica.

Abstract: RIEC is a scientific web of interaction, training of researchers, sharing and producing Postgraduate research with themes related to Science Teaching (EC). Interdisciplinarity, as a challenge in $\mathrm{EC}$, presents itself as a possibility to expand knowledge, promote dialogues, and partnerships through dialogue with other areas. With this, the present documentary research through the integrative review, investigates 
the journals of institutions linked to RIEC seeking to answer how many interdisciplinary studies / practices are present in the sections of reports of pedagogical experiences / practices in these journals and which of these reports used the research methodology -action and / or action research to reflect on teaching actions. The "interdisciplinary" descriptor was applied in conjunction with the study's inclusion criteria. We found 21 interdisciplinary reports / practices, distributed between the period 2011 to 2020 examined by content analysis, in which 15 reports used the researchaction / research-action methodology to reflect on the teaching performance in the experience reports, with most of them carried out with the use of logbooks as an instrument to help teachers' professional reflection. Therefore, through this investigation, we emphasize the importance of RIEC as a way of contributing to the dissemination of the theme of interdisciplinarity in EC.

Keywords: International network; Experience report; Pedagogical practice.

Resumen: RIEC es una red científica de interacción, formación de investigadores, intercambio y producción de investigación de Postgrado con temáticas relacionadas con la Enseñanza de las Ciencias (CE). La interdisciplinariedad, como desafío en la CE, se presenta como una posibilidad para expandir conocimientos, promover diálogos y alianzas a través del diálogo con otras áreas. Con esto, la presente investigación documental a través de la revisión integradora, investiga las revistas de instituciones vinculadas a la RIEC buscando dar respuesta a cuántos estudios / prácticas interdisciplinarias están presentes en las secciones de informes de experiencias / prácticas pedagógicas en estas revistas y cuáles de estos informes utilizaron. la metodología de la investigación -acción y / o investigación-acción para reflexionar sobre las acciones docentes. El descriptor "interdisciplinario" se aplicó junto con los criterios de inclusión del estudio. Se encontraron 21 informes / prácticas interdisciplinares, distribuidos entre el período 2011 a 2020 examinados por análisis de contenido, en los cuales 15 informes utilizaron la metodología investigación-acción / investigación-acción para reflexionar sobre el desempeño docente en los informes de experiencia, la mayoría de ellos realizados con el uso de bitácoras como instrumento de ayuda a la reflexión profesional de los docentes. Por ello, a través de esta investigación, destacamos la importancia de la RIEC como una forma de contribuir a la difusión del tema de la interdisciplinariedad en la CE.

Palabras-clave: Red internacional; Informe de experiencias; Práctica pedagógica.

\section{INTRODUÇÃO}

A Rede Internacional de Investigação em Ensino de Ciências (RIEC) é uma teia científica com interação, formação de pesquisadores, compartilhamento e produção de 
pesquisas de Pós-Graduação com temáticas relacionadas ao Ensino de Ciências (EC). Ela é uma parceria entre as seguintes instituições: Universidade Federal da Fronteira Sul (UFFS); Universidade Pedagógica Nacional (UPN); Universidade Regional Integrada do Alto Uruguai e das Missões (URI); Universidade de Passo Fundo (UPF); Universidade Regional do Noroeste do Estado do Rio Grande do Sul (UNIJUÍ); Instituto Federal Farroupilha (IFFar); Universidade Católica de Manizales, - Colombia; Corporacion Universitaria del Caribe; Fundación Universidad Autónoma de Colombia (RIEC, 2020).

O lançamento oficial da RIEC ocorreu no dia 14 de setembro de 2020, por meio de uma videoconferência apresentada no canal do Youtube, durante o V Congresso Internacional de Educação Científica e Tecnológica (V CIECITEC) ${ }^{\mathrm{i}}$ promovido pela URI- Campus de Santo Ângelo com o objetivo de promover e divulgar a educação cientifica e tecnológica no EC. Durante seu lançamento discutiram-se ações sobre o EC, e foram resgatados pontos abordados por Azevedo (2013): a perspectiva de renovação do EC, a avaliação do ensino, a aprendizagem do EC como uma apropriação e a discussão de conhecimentos por docentes e discentes, buscando o EC distante de um ensino tradicional que contempla a aprendizagem como recepção e transmissão.

Uma rede de pesquisa, investigação e/ou ensino é estabelecida por um grupo de pessoas, e/ou instituições que procura estudar assuntos formando uma teia de conhecimentos por meio das pesquisas, conectando os parceiros, saberes e circunstâncias gerando oportunidades e a capacidade de resolver problemas em grupo (LEITE et al., 2014). Por isso, a RIEC assim como outras redes de investigação, é relevante no auxílio com a produção do conhecimento científico no Brasil e no exterior, conectando parcerias investigativas, produção de conhecimentos e, assim, auxiliando a expansão, a consolidação e o fomento dos estudos no/sobre o EC (ALMEIDA; RUBINOLVIERA, 2019).

Considerando, a importância e benefícios de uma rede de investigação já citados, Sonnenwald (2007) evoca ainda, a interdisciplinaridade como fundamental na colaboração científica, rompendo com o conhecimento exclusivamente disciplinar, evidenciando o aporte de conhecimentos que podem ser incorporados as redes como a RIEC. A interdisciplinaridade, que é para França (2014) uma ação reflexiva que integra 
os sujeitos e os conhecimento permitindo diálogos com diferentes mundos, contextos e saberes.

Nesse sentido, a interdisciplinaridade no EC pode articular os conhecimentos, procurando estabelecer parcerias, ideias e conceitos para que seja diminuída a distância entre a teoria e prática, um campo de saber e outro (LEMKE; SCHEID, 2019). Logo, compreendemos que a interdisciplinaridade pode auxiliar no EC à medida que procura articular os conhecimentos científicos com as práticas cotidianas proporcionando um pensamento articulado com a realidade sócio, histórica e cultural, pressupondo a desconstrução e ruptura do tradicional e, o ensino por tarefas, no qual suas principais características são o compartilhamento, o encontro, o diálogo, não limitando-se apenas a superação da visão fragmentada das disciplinas (FAZENDA, 2001; FAZENDA, 2013).

Contudo, estudos demonstram que a interdisciplinaridade no EC é um desafio, uma revisão de Mozena e Ostermann (2014) realizada no período que compreende entre 1980 até 2012 encontrou 70 trabalhos que envolvem direta ou indiretamente a interdisciplinaridade no EC. Na revisão de literatura apresentada por Lemke e Scheid (2019) analisando as publicações com os descritores "Interdisciplinaridade no ensino de Ciências" na Biblioteca Brasileira de Teses e Dissertações, durante o período de 2002 à 2019, foram encontrados apenas 43 estudos sobre o assunto.

Assim, devido a partilha desses estudos sobre a interdisciplinaridade no EC, procuramos investigar nos periódicos da RIEC como a temática da interdisciplinaridade no EC vem apresentando-se com relação as práticas pedagógicas, por meio das seguintes questões: quantos estudos/práticas interdisciplinares estão presentes nas seções de relatos de experiências/práticas pedagógicas dos periódicos da rede RIEC? E, quais dos estudos interdisciplinares utilizam como metodologias a investigação-ação e/ou a pesquisa-ação para realizar reflexões sobre as ações docentes?

A escolha investigativa da metodologia da investigação-ação e/ou da pesquisaação conduziu-se em pesquisa solicitada no componente curricular de Tópicos Especiais (Investigação-Ação Crítica em Ensino de Ciências) do Programa de Pós-Graduação em Ensino de Ciências da UFFS.

\section{OS PERIÓDICOS DA RIEC}


Os periódicos, das instituições vinculadas à RIEC, são: Revista Contexto \& Educação, Tecné, Episteme y Didaxis (TED), Revista Praxis Pedagógica, Bio-grafia, Ensino de Ciências e Tecnologia em Revista (ENCITEC), Revista Insignare Scientia (RIS) e a Revista Brasileira de Ensino de Ciências e Matemática (RBECM).

A Revista Contexto \& Educação existe desde 1986 e, em 2004, passou a ser coordenada pelo Programa de Pós-Graduação em Educação nas Ciências (PPGEC/UNIJUÍ). Apresenta artigos, ensaios e resenhas de diferentes áreas do conhecimento. No ano de 2011 passou a adotar formato totalmente digital, a partir desse ano até o presente momento (UNIJUÍ, s.d.).

A TED existe desde 1991 e, a partir de 1998, tem realizado publicações contínuas. O periódico é publicado pela Faculdade de Ciências e Tecnologia da Universidade Pedagógica Nacional, seu escopo indica trabalhos de educação em ciências experimentais, matemática e tecnologia (TED, s.d.). De dois em dois anos existe a publicação de um número especial, no qual são publicados os artigos do Congresso Internacional para a Formação de Professores de Ciências.

A Práxis Pedagógica é uma publicação científica internacional, publicada semestralmente pela Minuto de Dios University Corporation (UNIMINUTO), com primeira edição em 1999. As contribuições aceitas são relacionadas à pedagogia praxeológica, social e participativa, didáticas específicas, inclusão social, inovações sociais na educação, ambientes de aprendizagem e narrativas de ensino (PRAXIS PEDAGOGICA, s.d.).

A revista colombiana Bio-grafia, também vinculada a Faculdade de Ciências e Tecnologia da Universidade Pedagógica Nacional, apresenta pesquisas no Ensino de Biologia com produções de professores em formação inicial e professorespesquisadores, sobre inovações, experiências, reflexões, propostas e pesquisas. Ela existe desde 2008 e sua periodicidade é semestral (BIO-GRAFIA, s.d.).

Já a ENCITEC é revista do Programa de Pós-Graduação Stricto Sensu em Ensino Científico e Tecnológico (PGEnCT/URI) publica estudos teóricos ou empíricos, relacionadas ao ensino de ciências, ensino de matemática, ensino de tecnologias, ensino 
de saúde ou áreas afins. Seu primeiro número foi no ano de 2011 e conta com publicação quadrimestral desde 2019 (ENCITEC, s.d.).

A RIS é ligada ao Grupo de Pesquisas em Ensino de Ciências e Matemática (GEPECIEM), vinculada ao Programa de Pós-Graduação em Ensino de Ciências (PPGEC/UFFS), existindo desde 2018. O periódico publica: produções de pesquisa originais, relatos de experiências, propostas didáticas, resenhas e biografias no Ensino de Ciências (RIS, s.d.).

A RBECM existe também desde 2018, de responsabilidade do Programa de Pósgraduação em Ensino de Ciências e Matemática (PPGECM), com pesquisa na área de ensino/aprendizagem de Ciências e Matemática. Nela são aceitos artigos de: investigação, revisão da literatura, fundamentação teórica, metodologia da pesquisa educacional com relevância direta para a investigação em ensino de Ciências e Matemática, relatos de experiências, propostas didáticas e produtos Educacionais (RBECM, s.d.).

O Quadro 1 que segue abaixo apresenta o número de edições (entre parênteses) e, o número de artigos e/ou relatos de experiência distribuídos por anos de 2011 a 2020, ao total são 2311 publicados nos sete periódicos. publicação.

Quadro 1 - $\mathrm{N}^{\mathrm{o}}$ de artigos e/ou relatos de experiência da RIEC, por periódicos e ano de

\begin{tabular}{|c|c|c|c|c|c|c|c|c|}
\hline Ano & $\begin{array}{c}\text { Contexto } \\
\& \\
\text { Educação }\end{array}$ & TED & $\begin{array}{c}\text { Práxis } \\
\text { Pedagógica }\end{array}$ & $\begin{array}{c}\text { Bio- } \\
\text { Grafia }\end{array}$ & ENCITEC & RIS & RBECM & $\mathrm{N}^{\mathrm{o}}$ Total \\
\hline 2011 & (2) 19 & (2) 12 & - & (3) 82 & (2) 25 & - & - & 138 \\
\hline 2012 & (2) 21 & (2) 19 & - & (2) 20 & (2) 12 & - & - & 72 \\
\hline 2013 & (3) 26 & (2) 17 & - & (3) 112 & (2) 11 & - & - & 166 \\
\hline 2014 & (3) 29 & $\begin{array}{l}(3) \\
130\end{array}$ & - & (2) 29 & (2) 14 & - & - & 202 \\
\hline
\end{tabular}




\begin{tabular}{|l|c|c|c|c|c|c|c|c|}
\hline $\mathbf{2 0 1 5}$ & (3) 24 & (2) 16 & - & (3) 185 & (2) 13 & - & - & 238 \\
\hline $\mathbf{2 0 1 6}$ & (3) 30 & $\begin{array}{c}\text { (3) } \\
132\end{array}$ & - & (3) 68 & (2) 14 & - & - & 254 \\
\hline $\mathbf{2 0 1 7}$ & (3) 31 & (2) 23 & - & (3) 212 & (2) 7 & - & - & 273 \\
\hline $\mathbf{2 0 1 8}$ & (3) 52 & 123 & - & (2) 24 & (3) 18 & (3) 31 & (2) 16 & 264 \\
\hline $\mathbf{2 0 1 9}$ & (3) 53 & (2) 22 & (1) 7 & (3) 224 & (3) 34 & (4) 94 & (2) 24 & 458 \\
\hline $\mathbf{2 0 2 0}$ & (3) 60 & (2) 26 & (1) 7 & (2) 22 & (3) 37 & (2) 54 & (3) 40 & 246 \\
\hline Total & $\mathbf{3 4 5}$ & $\mathbf{5 2 0}$ & $\mathbf{1 4}$ & $\mathbf{9 7 8}$ & $\mathbf{1 8 5}$ & $\mathbf{1 7 9}$ & $\mathbf{8 0}$ & $\mathbf{2 3 1 1}$ \\
\hline
\end{tabular}

Fonte: Autores, 2021.

Em síntese, as instituições que fazem parte da RIEC abrigam, atualmente, sete periódicos cujo escopo atende aos propósitos da rede. A partir de 2019 todas as revistas publicam pelo menos uma edição anualmente, configurando-se 2019 como o ano de maior número de publicações, com 458 artigos e/ou relatos de experiência envolvendo os periódicos da RIEC.

\section{METODOLOGIA}

O presente estudo é uma pesquisa documental com uma revisão integrativa, com seis fases sendo elas: a elaboração das perguntas norteadoras; realização da busca/amostra; coleta dos dados; análise crítica dos estudos da revisão e, discussão e apresentação dos dados (SOUZA; SILVA; CARVALHO, 2010). Para isso, baseamos o estudo nos seguintes questionamentos: quantos estudos/práticas interdisciplinares estão presentes nas seções de relatos de experiências/práticas pedagógicas dos periódicos da rede RIEC? E, quais dos estudos interdisciplinares utilizam como metodologias a investigação-ação e/ou a pesquisa-ação para realizar reflexões sobre as ações docentes? 
Para responder as questões norteadoras do estudo, investigamos os periódicos das instituições que fazem parte da RIEC, citados no tópico anterior desse estudo. Como descritor utilizamos "interdisciplinar" e suas combinações nas línguas portuguesa e inglesa. Os critérios de inclusão definidos para a seleção desse estudo foram: todos os artigos com experiências pedagógicas e/ou relatos de experiências relacionados ao descritor "interdisciplinar". A amostra do estudo é composta por 21 relatos de experiências/práticas pedagógicas, demonstrados no Quadro 2. O período estabelecido para a busca foi definido de 2011 a 2020, devido as publicações dos periódicos ocorrem de forma digital, somente a partir de 2011, e não termos tido acesso a todos os números impressos publicados anteriormente.

A análise baseou-se em análise de conteúdo de Bardin (2011). Procurando responder a segunda questão do estudo, realizou-se uma busca das metodologias de investigação-ação e pesquisa-ação nos 21 relatos/experiências interdisciplinares encontrados.

Para uma melhor leitura e adequação ao espaço dos quadros 2 e 3 empregamos a identificação dos artigos (ID) com R1, R2, R3...R21 como códigos, e as referências desses relatos encontram-se ao final desse estudo devidamente referenciados e, com links de acesso, fornecidos como nota final.

Quadro 2 Relatos de experiências interdisciplinares presente nos periódicos que compõe a RIEC.

\begin{tabular}{|c|c|c|c|}
\hline ID & Título do Relato & Periódico & Ano \\
\hline R1 & $\begin{array}{c}\text { Construção de conhecimentos práticos, baseada na práxis de } \\
\text { um professor na formação }\end{array}$ & Bio-grafia & 2012 \\
\hline R2 & $\begin{array}{c}\text { O ensino de ciências e os temas transversais: práticas } \\
\text { pedagógicas no contexto escolar }\end{array}$ & Contexto \& Educação & 2014 \\
\hline R3 & $\begin{array}{c}\text { Formação de professores e educação ambiental: uma } \\
\text { abordagem interdisciplinar na construção de saberes e fazeres } \\
\text { docentes na Biologia e Geografia }\end{array}$ & Bio-grafia & 2015 \\
\hline R4 & $\begin{array}{c}\text { Ecologia como prática educacional interdisciplinar entre } \\
\text { educação física e tecnologia }\end{array}$ & Práxis Pedagógica & 2016 \\
\hline R5 & $\begin{array}{c}\text { Construção de Recursos Didáticos para o Empoderamento } \\
\text { Científico e Ambiental das Questões Hídricas }\end{array}$ & TED & 2016 \\
\hline R6 & $\begin{array}{c}\text { Ação da biologia PIBID na educação básica por meio da } \\
\text { abordagem temática Freireano: ações formativas em } \\
\text { Educação Ambiental }\end{array}$ & Bio-grafia & 2017 \\
\hline R7 & $\begin{array}{c}\text { Contribuições da ferramenta KAHOOT! Na compreensão dos } \\
\text { conceitos da área de ciências da natureza }\end{array}$ & TED & 2018 \\
\hline R8 & $\begin{array}{c}\text { Aprendizagem criativa na construção de jogos digitais: uma } \\
\text { proposta educativa no ensino de ciências para crianças }\end{array}$ & TED & 2018 \\
\hline
\end{tabular}




\begin{tabular}{|c|c|c|c|}
\hline R9 & $\begin{array}{c}\text { Uma experiência interdisciplinar: ensino de áreas e volumes } \\
\text { usando um recurso computacional visual }\end{array}$ & TED & 2018 \\
\hline $\mathbf{R} 10$ & $\begin{array}{c}\text { As contribuições de um planejamento interdisciplinar com } \\
\text { temáticas de ciências numa amostra de alunos com } \\
\text { dificuldades de aprendizagem }\end{array}$ & Contexto \& Educação & 2018 \\
\hline $\mathbf{R} 11$ & $\begin{array}{l}\text { Experiências na formação inicial: primeiras interações com a } \\
\text { sala de aula }\end{array}$ & RIS & 2019 \\
\hline $\mathbf{R} 12$ & $\begin{array}{l}\text { Desastre Ambiental do Exxon Valdez: temática de } \\
\text { planejamento didático no ensino de Biologia }\end{array}$ & RIS & 2019 \\
\hline $\mathbf{R} 13$ & $\begin{array}{c}\text { Minha primeira experiência como Professora de Biologia: } \\
\text { desastres e esperanças }\end{array}$ & RIS & 2019 \\
\hline R14 & $\begin{array}{c}\text { Construção de um biodigestor: uma proposta de ensino } \\
\text { interdisciplinar para escolas do campo }\end{array}$ & RIS & 2019 \\
\hline $\mathbf{R} 15$ & Trabalhando o conceito de densidade Educação Básica & RIS & 2019 \\
\hline $\mathbf{R} 16$ & $\begin{array}{l}\text { O desenvolvimento de estratégias de ensino para a promoção } \\
\text { da saúde na formação docente continuada }\end{array}$ & Contexto \& Educação & 2019 \\
\hline $\mathbf{R} 17$ & $\begin{array}{l}\text { As ações docentes em um projeto interdisciplinar nas aulas de } \\
\text { ciências nos anos iniciais do ensino fundamental. }\end{array}$ & ENCITEC & 2019 \\
\hline $\mathbf{R} 18$ & $\begin{array}{c}\text { A escrita e a leitura promovidas pela experimentação } \\
\text { contextualizada e interdisciplinar na construção de conceitos } \\
\text { científicos }\end{array}$ & ENCITEC & 2019 \\
\hline R19 & $\begin{array}{c}\text { Alimentação saudável e atividade física na escola através de } \\
\text { uma abordagem contextualizada e interdisciplinar }\end{array}$ & Contexto \& Educação & 2020 \\
\hline R20 & $\begin{array}{l}\text { Projeto engenharia de trânsito: robótica no semáforo de } \\
\text { cruzamento. }\end{array}$ & ENCITEC & 2020 \\
\hline $\mathbf{R 2 1}$ & $\begin{array}{l}\text { O vídeo como recurso didático: uma intervenção pedagógica } \\
\text { sobre o uso da água. }\end{array}$ & ENCITEC & 2020 \\
\hline
\end{tabular}

Fonte: Autores, 2021.

Ressaltamos que no período RBECM não foram encontradas as práticas pedagógicas/experiências interdisciplinares no EC, conforme os critérios de inclusão estabelecidos na metodologia. Os dados foram coletados em 21 de dezembro de 2020.

\section{RESULTADOS E DISCUSSÕES}

Nessa ocasião, procuramos responder a nossa primeira questão norteadora sobre o número de estudos/práticas interdisciplinares que estão presentes nos relatos de experiências/práticas pedagógicas dos periódicos da RIEC e identificamos 21 relatos já citados no Quadro 2 desse artigo, com título, autores, periódico e ano. Os estudos dividiram-se entre a Revista Práxis Pedagógica, Bio-Grafia, Contexto \& Educação, ENCITEC, TED e RIS. A RBECM não apresentou nenhum estudo a respeito da interdisciplinaridade no EC, no período em que efetuamos a busca com os descritores na revista. 
Os periódicos com maior incidência de relatos de experiências/práticas pedagógicas são a RIS (05), Contexto \& Educação (04) e a TED (04). Esses números podem ser explicados pelos grupos de pesquisas que estão envolvidos nos periódicos citados, que vinculados a programas de Pós-Graduação realizam discussões e reflexões sobre a formação profissional docente em seus cursos no EC, possuindo inclusive linhas de pesquisa sobre o assunto. Exemplificando com a RIS, temos seu vínculo ao PPGEC/UFFS que possui duas linhas de pesquisa: Linha 1: Políticas Educacionais e Currículo e a Linha 2: Formação de Professores e Práticas Pedagógicas. A Linha 1 discute questões sobre o currículo e interdisciplinaridade, e a Linha 2 sobre a formação dos professores e seus projetos de formação profissional docente, ambos que se encaixam em nossa pesquisa (UFFS, 2019).

Ao analisar o nível de ensino das pesquisas encontradas nos periódicos, na sua maioria (16), os estudos concentraram-se na Educação Básica, 04 estudos concentramse apenas no Ensino Superior e 01 abrange o Ensino Superior e a Educação Básica. Dessa forma, fica evidenciado que a investigação-ação/pesquisa-ação como uma forma do professor da Educação Básica repensar sua práxis e, assim refletir sobre suas ações a fim de desenvolver um pensamento crítico para auxiliar os discentes no processo de ensino e aprendizagem. Então, como Radetzke (2019) relata, o compartilhamento de experiências por parte dos professores da Educação Básica pelo processo de investigar e refletir a própria prática desencadeia ações no ensino entre docentes e discentes proporcionando questionamentos, saberes e vivências no ambiente escolar a partir das contribuições formativas.

Seguindo a investigação para o segundo questionamento central do estudo: "quais dos estudos interdisciplinares utilizaram como metodologias a investigação-ação e/ou a pesquisa-ação para realizar reflexões sobre as ações docentes?" constatamos que 15/21 estudos empregaram a investigação-ação/pesquisa-ação para investigar a própria prática. Nessa direção, Zeichner (1993) afirma que a reflexão dos professores, por meio de suas ações é também um processo de produção de conhecimentos, e que não pode limitar-se apenas as Universidades e aos Centros de investigação, se faz necessário ampliar para os diferentes níveis de educação. Especificamente, sobre os 15 relatos que 
empregavam a Investigação-ação/pesquisa-ação, 10 se concentravam na Educação

Básica, realizando o movimento de reflexão dos professores que Zeichner propõe.

O Quadro 3 que segue, apresenta as disciplinas com referência a Educação Básica e os componentes curriculares quanto ao Ensino Superior envolvidos nas ações interdisciplinares do EC, o nível de ensino, uma síntese sobre o relato comentando o que foi realizado e, os componentes que apontam ou não a metodologia da Investigaçãoação/pesquisa-ação. Nesse Quadro, quando se refere a Ciências da Natureza estamos utilizando o termo do Ensino Médio (Educação Básica) para descrever as disciplinas de Biologia, Química e Física (BRASIL, 2018).

O Quadro 3 apresenta as seguintes siglas: Componentes Curriculares (CC); Nível de ensino (NE); Educação Básica (EB); Ensino Superior (ES).

Esclarecemos que aplicamos nesse estudo os termos investigação-ação e pesquisaação porque, conforme Tripp (2005), a investigação-ação é um tipo de pesquisa-ação que procura, por meio de um ciclo, investigar e refletir a prática pedagógica, procurando melhorá-la.

Quadro 3 - Resumo dos relatos de experiências/práticas pedagógicas nos periódicos da RIEC.

\begin{tabular}{|c|c|c|c|c|}
\hline ID & $\begin{array}{l}\text { CC/disciplinas } \\
\text { interdisciplinar }\end{array}$ & $\mathbf{N E}$ & Síntese & $\begin{array}{l}\text { Metodologia e } \\
\text { instrumentos: }\end{array}$ \\
\hline R1 & $\begin{array}{l}\text { CC do Curso de Ciências } \\
\text { Biológicas: Prática } \\
\text { pedagógica e didática } \\
\text { específica II. }\end{array}$ & $\mathrm{ES}$ & $\begin{array}{l}\text { Reflexão realizada no espaço } \\
\text { acadêmico sobre os } \\
\text { conhecimentos pedagógicos e o } \\
\text { ser professor; descrição da } \\
\text { prática pedagógica, suas } \\
\text { respectivas reflexões. }\end{array}$ & $\begin{array}{l}\text { diário de } \\
\text { bordo e relato } \\
\text { autobiográfico, } \\
\text { metodologia } \\
\text { da } \\
\text { investigação- } \\
\text { ação. }\end{array}$ \\
\hline $\mathbf{R 2}$ & $\begin{array}{l}\text { Biologia, física, química, } \\
\text { geografia, história, } \\
\text { matemática, português, } \\
\text { educação física. }\end{array}$ & EB & $\begin{array}{l}\text { Apresenta uma proposta de } \\
\text { inserção dos temas transversais } \\
\text { Saúde, Meio Ambiente e } \\
\text { Orientação Sexual no contexto } \\
\text { escolar, através de práticas. }\end{array}$ & $\begin{array}{l}\text { diários de } \\
\text { bordo; } \\
\text { metodologia } \\
\text { da } \\
\text { investigação- } \\
\text { ação. }\end{array}$ \\
\hline $\mathbf{R 3}$ & Biologia e geografia & EB & $\begin{array}{l}\text { Estudantes de Licenciatura e } \\
\text { professores de Biologia e } \\
\text { Geografia no planejamento, } \\
\text { discussão, reflexão e busca de } \\
\text { práticas pedagógicas alternativas } \\
\text { relacionadas à problemática } \\
\text { socioambiental, e realização de } \\
\text { aulas interdisciplinares sobre a } \\
\text { temática. }\end{array}$ & $\begin{array}{l}\text { Pesquisa-ação- } \\
\text { participativa; } \\
\text { ação-reflexão- } \\
\text { ação; diário de } \\
\text { bordo. }\end{array}$ \\
\hline
\end{tabular}




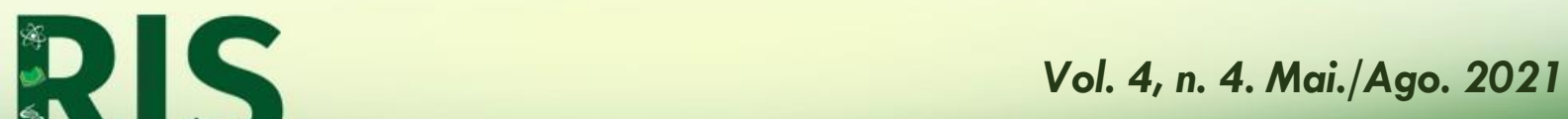

\begin{tabular}{|c|c|c|c|c|}
\hline R4 & Educação física, e tecnologia & EB & $\begin{array}{c}\text { Proposta interdisciplinar sobre } \\
\text { ecologia aplicada na educação } \\
\text { básica. }\end{array}$ & $\begin{array}{l}\text { Não cita a } \\
\text { metodologia } \\
\text { da } \\
\text { investigação- } \\
\text { ação e/ou } \\
\text { pesquisa-ação. }\end{array}$ \\
\hline R5 & Ciências da Natureza & EB & $\begin{array}{c}\text { O projeto constrói materiais } \\
\text { lúdico-didáticos e virtuais para } \\
\text { serem utilizados por professores } \\
\text { e alunos de diferentes níveis de } \\
\text { ensino no Brasil através de um } \\
\text { site educativo. }\end{array}$ & $\begin{array}{l}\text { diários de } \\
\text { campo; } \\
\text { metodologia } \\
\text { da pesquisa- } \\
\text { ação. }\end{array}$ \\
\hline R6 & Ciências da Natureza & EB & $\begin{array}{l}\text { Processo formativo } \\
\text { interdisciplinar com professores e } \\
\text { licenciandos sobre a abordagem } \\
\text { temática dos problemas } \\
\text { ambientais, consequentes riscos à } \\
\text { saúde da comunidade. }\end{array}$ & $\begin{array}{l}\text { Metodologia a } \\
\text { Pesquisa-ação. }\end{array}$ \\
\hline R7 & Ciências da Natureza. & EB & $\begin{array}{c}\text { Utilização da plataforma do } \\
\text { Kahoot em conceitos de Ciências } \\
\text { da Natureza. }\end{array}$ & $\begin{array}{l}\text { Diários de } \\
\text { bordo; } \\
\text { Metodologia } \\
\quad \text { da } \\
\text { investigação- } \\
\text { ação. } \\
\end{array}$ \\
\hline $\mathbf{R 8}$ & Ciências da Natureza. & $\mathrm{EB}$ & $\begin{array}{l}\text { Experiência de criação de jogos } \\
\text { digitais com o uso do Scratch. }\end{array}$ & $\begin{array}{c}\text { Não cita a } \\
\text { metodologia } \\
\text { da } \\
\text { investigação- } \\
\text { ação e/ou } \\
\text { pesquisa-ação. }\end{array}$ \\
\hline R9 & ta Insiqnare S & Ien & $\begin{array}{l}\text { Experiência interdisciplinar sobre } \\
\text { áreas e volumes utilizando um } \\
\text { recurso de programação de } \\
\text { software: Visual G. } \\
\text { ilas }\end{array}$ & $\begin{array}{l}\text { Não cita a } \\
\text { metodologia } \\
\text { da } \\
\text { investigação- } \\
\text { ação e/ou } \\
\text { pesquisa-ação. }\end{array}$ \\
\hline R10 & $\begin{array}{l}\text { Ciências da Natureza, } \\
\text { Matemática e Língua } \\
\text { Portuguesa. }\end{array}$ & EB & $\begin{array}{l}\text { Proposta interdisciplinar com } \\
\text { temáticas de Ciências no } \\
\text { desempenho escolar de alunos } \\
\text { com dificuldades de } \\
\text { aprendizagem. }\end{array}$ & $\begin{array}{l}\text { Não cita a } \\
\text { metodologia } \\
\text { da } \\
\text { investigação- } \\
\text { ação e/ou } \\
\text { pesquisa-ação. }\end{array}$ \\
\hline R11 & $\begin{array}{l}\text { CC do Curso de Ciências } \\
\text { Biológicas: Prática de Ensino } \\
\text { em Ciências e Biologia III - } \\
\text { Metodologia e Didática no } \\
\text { Ensino de Ciências e Biologia }\end{array}$ & ES & $\begin{array}{l}\text { Experiências em sala de aula na } \\
\text { constituição do Professor de } \\
\text { Ciências e Biologia. }\end{array}$ & $\begin{array}{l}\text { Diários de } \\
\text { bordo, e } \\
\text { autoscopia, } \\
\text { Metodologia } \\
\text { da } \\
\text { investigação- } \\
\text { ação. }\end{array}$ \\
\hline R12 & $\begin{array}{l}\text { CC do Curso de Ciências } \\
\text { Biológicas: Prática de Ensino } \\
\text { em Ciências e Biologia III - } \\
\text { Metodologia e Didática no } \\
\text { Ensino de Ciências e Biologia }\end{array}$ & $\begin{array}{c}\mathrm{ES} / \mathrm{E} \\
\mathrm{B}\end{array}$ & $\begin{array}{l}\text { Experiência interdisciplinar com } \\
\text { a temática o derrame de Petróleo } \\
\text { do Navio Exxon Valdez. }\end{array}$ & $\begin{array}{l}\text { Diários de } \\
\text { bordo, } \\
\text { formação } \\
\text { docente. } \\
\text { Metodologia } \\
\text { da } \\
\text { investigação- }\end{array}$ \\
\hline
\end{tabular}




\begin{tabular}{|c|c|c|c|c|}
\hline & & & & ação. \\
\hline R13 & $\begin{array}{l}\text { CC do do Curso de Ciências } \\
\text { Biológicas: Prática de Ensino } \\
\text { em Ciências e Biologia III - } \\
\text { Metodologia e Didática no } \\
\text { Ensino de Ciências e } \\
\text { Biologia. }\end{array}$ & $\mathrm{ES}$ & $\begin{array}{l}\text { Experiência de elaboração de um } \\
\text { planejamento interdisciplinar de } \\
\text { aulas direcionadas ao } 2^{\circ} \text { ano do } \\
\text { Ensino Médio para o componente } \\
\text { curricular escolar Biologia. }\end{array}$ & $\begin{array}{l}\text { Cita a } \\
\text { metodologia } \\
\text { da } \\
\text { Investigação- } \\
\text { formação- } \\
\text { ação. }\end{array}$ \\
\hline R14 & $\begin{array}{c}\text { Entre as disciplinas de } \\
\text { Biologia, Física e Química, }\end{array}$ & EB & $\begin{array}{c}\text { por um professor da Educação } \\
\text { Básica, com estudantes do } 2^{\circ} \text { ano } \\
\text { do Ensino Médio de uma escola } \\
\text { estadual, em Itatiba do Sul - RS, } \\
\text { integrante do TCC do autor } \\
\text { principal. }\end{array}$ & $\begin{array}{l}\text { Diários /falas } \\
\text { dos alunos. } \\
\text { Metodologia } \\
\text { da } \\
\text { investigação- } \\
\text { ação. }\end{array}$ \\
\hline R15 & Ciências da Natureza & EB & $\begin{array}{c}\text { Experiência interdisciplinar } \\
\text { realizada em uma turma do } 9^{\circ} \\
\text { ano do ensino fundamental de } \\
\text { uma escola pública sobre } \\
\text { densidade. }\end{array}$ & $\begin{array}{l}\text { Metodologia } \\
\text { da } \\
\text { investigação- } \\
\text { ação. }\end{array}$ \\
\hline R16 & Ciências da Natureza. & EB & $\begin{array}{c}\text { Oficinas pedagógicas } \\
\text { interdisciplinares sobre a } \\
\text { promoção da saúde na formação } \\
\text { docente continuada. }\end{array}$ & $\begin{array}{c}\text { Apresenta a } \\
\text { metodologia } \\
\text { descrita como } \\
\text { Pesquisa-ação. }\end{array}$ \\
\hline R17 & Ciências da Natureza. & EB & $\begin{array}{c}\text { Práticas interdisciplinares } \\
\text { desenvolvidas sobre os impactos } \\
\text { ambientais causados pela } \\
\text { humanidade. }\end{array}$ & Pesquisa-ação. \\
\hline R18 & Ciências da Natureza. & EB & $\begin{array}{l}\text { Experimentação interdisciplinar } \\
\text { sobre Vitamina C e sucos. }\end{array}$ & $\begin{array}{l}\text { Professor } \\
\text { pesquisador; } \\
\text { Metodologia } \\
\text { da } \\
\text { investigação- } \\
\text { ação. }\end{array}$ \\
\hline R19 & $\begin{array}{l}\text { Ciências da Natureza e } \\
\text { ta | Educação Física. }\end{array}$ & $\begin{array}{l}\text { EB } \\
i e r\end{array}$ & $\begin{array}{c}\text { Intervenção pedagógica } \\
\text { interdisciplinar sobre o tema } \\
\text { alimentação/prática de atividade } \\
\text { física. }\end{array}$ & $\begin{array}{l}\text { Diários de } \\
\text { bordo; } \\
\text { Metodologia } \\
\text { da pesquisa- } \\
\text { ação. }\end{array}$ \\
\hline R20 & $\begin{array}{c}\text { Ciências da Natureza e } \\
\text { Matemática. }\end{array}$ & EB & $\begin{array}{l}\text { Experiências interdisciplinares da } \\
\text { robótica educacional para a } \\
\text { construção de projetos } \\
\text { interdisciplinares no contexto da } \\
\text { educação básica. }\end{array}$ & $\begin{array}{l}\text { Não cita a } \\
\text { metodologia } \\
\text { da } \\
\text { investigação- } \\
\text { ação e/ou } \\
\text { pesquisa-ação. }\end{array}$ \\
\hline R21 & Ciências da Natureza. & EB & $\begin{array}{c}\text { Intervenção pedagógica } \\
\text { interdisciplinar sobre o uso } \\
\text { consciente da água potável. }\end{array}$ & $\begin{array}{l}\text { Não cita a } \\
\text { metodologia } \\
\text { da } \\
\text { investigação- } \\
\text { ação e/ou } \\
\text { pesquisa-ação. }\end{array}$ \\
\hline
\end{tabular}

Fonte: Autores, 2021.

Embora compreendamos que o foco da pesquisa era o EC, é interessante olhar que os professores da Educação Básica não ampliaram seus estudos para além das disciplinas próximas, pois 09 (nove) relatos concentraram-se exclusivamente com a 
interdisciplinaridade nas Ciências da Natureza, que dentro da Base Nacional Comum Curricular (BNCC) articula a Biologia, a Física e a Química com a sistematização das aprendizagens das Ciências no Ensino Fundamental, que possui as mesmas habilidades e competências específicas (BRASIL, 2018). Para isso, consideramos interessante olhar para Paviani (1993), no sentido de que é necessário que os professores busquem a interdisciplinaridade para além de suas áreas, não porque esses se fazem somatórios, mas porque diferentes níveis e âmbitos em múltiplas áreas podem proporcionar uma ampliação e variação de múltiplos conhecimentos.

Outra relação interdisciplinar nos estudos são as Ciências da Natureza e a Matemática, que apesar de comporem um mesmo núcleo tradicionalmente, para Lavaqui e Batista (2007) proporcionam relações que preparam os discentes ao exercício da cidadania com reflexões de práticas interdisciplinares de áreas não tão exploradas nesse sentido. No Quadro 3, também observamos a interdisciplinaridade entre as Ciências da Natureza e a Educação Física, principalmente com os aspectos de corpo humano, saúde e alimentação saudável. Contudo, cabe ressaltar que conforme Lemke e Scheid (2020), na Educação Básica entre essas disciplinas podem ocorrer diferentes diálogos, para além do corpo humano e saúde, como as relações de meio ambiente, funções/regulações dos movimentos corporais, velocidade, sendo capaz de a interdisciplinaridade entre elas promover uma aprendizagem mais contextualizada e, significativa para a formação integral dos alunos da Educação Básica.

Com relação a investigação-ação/pesquisa-ação os relatos compreendem de um modo geral, conforme Azevedo (2013) uma sequência de ações/fases que possuem diferentes nomenclaturas, mas seguem os mesmos objetivos, que são: a delimitação de um tema/problema; o conhecimento e a situação de estudo; o problema em si; o levantamento de hipóteses para resolução de problemas; o planejamento das ações; e, análise de resultados, tipificando como Investigação-ação/pesquisa-ação. Evidentemente que não podemos simplificar as atividades científicas de investigação da própria prática, por isso apresentamos os conceitos, instrumentos e, referencias que os estudos encontrados na pesquisa expõem para tipificar a Investigação-ação/pesquisa-ação.

Os relatos de experiências/práticas pedagógicas, com exceção dos: R4, R8, R9, R10, R20 e R21, procuram reconhecer o conhecimento na ação, ou seja, em sua própria 
prática pedagógica enquanto professor, principalmente devido as necessidades de buscar soluções para novas situações que surgem na rotina de sala de aula (AZEVEDO, 2013). R4, R8, R9, R10, R20 e R21 não se enquadram na Investigação-ação/pesquisa-ação pois R4 não referiu como desenvolveu o relato em relação à metodologia; e os demais (R8, R9, R10, R20 e R21) não citaram como metodologias a investigação-ação e nem a pesquisa-ação. Assim, conforme Zeichner (1993), esses relatos são práticas reflexivas e podem proporcionar ponderações aos docentes sobre seu desenvolvimento profissional, no entanto, não se enquadram como investigação-ação ou pesquisa-ação.

Como um dos componentes investigativos, para o professor realizar a Investigação-ação/pesquisa-ação, encontramos em alguns estudos (R1, R2, R3, R5, R7, R11, R12, R14, R19) a presença dos diários de bordo como ferramenta de reflexão do docente. Essas correspondem às considerações de Pórlan e Martín (1991), em que o diário é um guia para a investigação, no qual estão presentes as crenças, concepções e relações de sua prática pedagógica. Zabalza (1994) propõe que os diários são instrumentos que exploram a atuação profissional, promovendo feedbacks e estímulos para as reflexões docentes.

Consoante a isso, os diários desempenham a escrita e a narração de fatos e acontecimentos pedagógicos que levam o professor a refletir sobre a própria prática, porque, conforme Zabalza (1994), escrever em um diário não pode ser mecânico e sem reflexão. Para tal, com as ponderações de Pórlan e Martín (1991), podemos afirmar que os diários são instrumentos de uma prática reflexiva que oportuniza a tomada de consciência do professor, favorecendo conexões, e proporcionando o processo de investigação, ação e reflexão da própria prática.

Nos relatos de experiências/práticas pedagógicas:R1, R3, R6, R11, R13, R15, R18 aparecem os conceitos de "professor reflexivo" que, como afirma Azevedo (2013), são um dos elementos fundamentais da Investigação-ação/pesquisa-ação. Além de estar dentre os aspectos da investigação-ação e da pesquisa-ação, para Zeichner (1993), o professor reflexivo é um fator que colabora para que os docentes possam melhorar o ensino começando pela reflexão de suas experiências e, muitas vezes, motivados também pelas experiências dos outros professores e seus alunos. 
Dessa forma, ao desempenhar o papel reflexivo, o professor realiza um diálogo de possibilidades e desafios que permite olhar para suas aulas como um espaço de ensino e aprendizagem, não apenas dos alunos, mas de sua constituição profissional docente (RADETZKE, 2019). De modo geral, os 15 relatos de experiência/ práticas pedagógicas que envolviam a Investigação-ação/pesquisa-ação apresentam pelo menos uma das 11 características citadas por Tripp (2005) como fundamentais para a pesquisa-ação. A característica que todos apresentam são pesquisas voltadas ao desenvolvimento profissional do professor. As pesquisas identificadas como: R1, R2, R3, R5, R7, R11, R12, R13, R14, R15, R16, R17, R18 e R19 possuíam um sentido de continuidade reflexiva, não repetida e ocasional, em que procuravam por meio das reflexões docentes trabalhar os aspectos das situações da Educação Básica e/ou do Ensino Superior, o que para Tripp (2005) identifica-se como a característica da Investigação-ação/pesquisaação.

Em síntese, podemos inferir que a RIEC, com menos de um ano de atuação, vem se constituindo como uma teia científica em construção e aprimoramento das pesquisas no EC. Nesse sentido, temos a expectativa de que a rede terá crescimento com relação as temáticas da interdisciplinaridade e, investigação-ação/pesquisa-ação ao longo do desenvolvimento das integrações, formações de pesquisadores e compartilhamento das produções das pesquisas de Pós-Graduação das universidades, centros e os periódicos a ela associados.

\section{CONCLUSÃO}

Como resultados obtidos na pesquisa documental realizada, cujo corpus distribuiu-se em sete periódicos relacionados a RIEC, foram encontrados 21 relatos/práticas pedagógicas interdisciplinares distribuídos entre 2011 e 2020, em sua maioria realizado na Educação Básica (17 relatos de experiências/práticas pedagógicas), nas Ciências da Natureza (09 relatos de experiências/práticas pedagógicas).

Com relação à investigação-ação/pesquisa-ação, 15 dos 21 relatos de experiências/práticas pedagógicas encontrados nos periódicos da RIEC, utilizaram a investigação-ação/pesquisa-ação para analisar as práticas pedagógicas sistematizando os saberes das experiências, tendo o diário de bordo/formação como instrumento de 
acompanhamento e incorporação do hábito de registrar as memórias das aulas e possibilitando reflexões sobre suas ações.

Embora reconhecendo as limitações do presente estudo, ressaltamos a importância dos periódicos envolvidos na RIEC que, por meio de seus relatos de experiências e práticas pedagógicas, contribuem para divulgar o tema da interdisciplinaridade no EC. Outrossim, as pesquisas que englobam interdisciplinaridade, investigaçãoação/pesquisa-ação, apesar de encontrarem-se com um número de 21 estudos, tendem a futuramente a aumentar seu quantitativo, tendo em vista a construção científica que a rede pode estimular sobre essa temática.

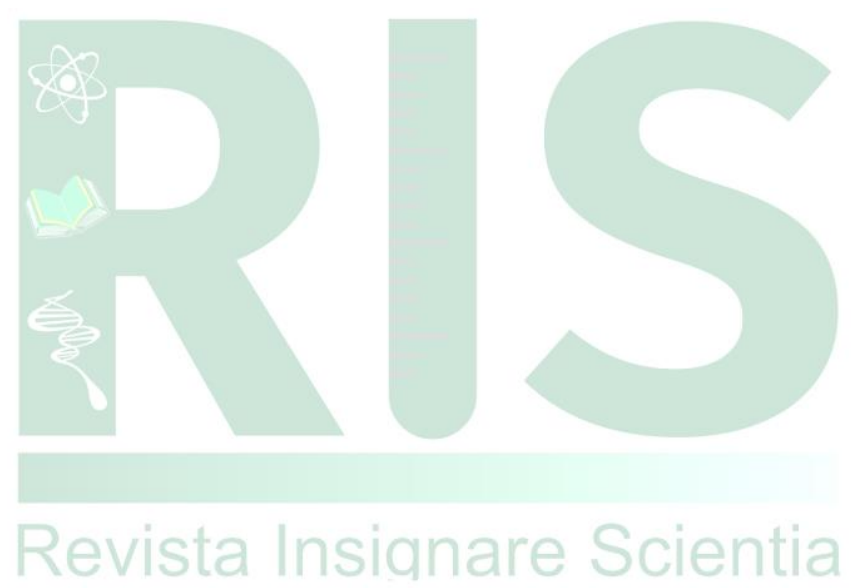




\section{REFERENCIAS}

ALMEIDA, Jalcione. RUBIN-OLIVEIRA, Marlize. Interdisciplinaridade no sistema nacional e pós-graduação e desafios a avaliação. In: RODRIGUES, Leo Peixoto;

ALMEIDA, Jalcione; COELHO, Gabriel Bandeira. Ciência, interdisciplinaridade e avaliação CAPES. 1 ed., Jundiaí-SP, Paco editorial, 2019.

AZEVEDO, Maria Nizete. Ensinar Ciências e pesquisa-ação: saberes docentes em elaboração. Jundiaí, Paco Editorial: 2013.

BARDIN, Laurence. Análise de conteúdo. São Paulo: Edições 70, 2011.

BRASIL. Ministério da Educação. Base Nacional Comum Curricular - Educação é a Base, 2018. Disponível em: http://basenacionalcomum.mec.gov.br/abase/\#medio/aarea-de-ciencias-da-natureza-e-suas-tecnologias . Acesso em: 20 jan. 2021.

CAPES, Coordenação de Aperfeiçoamento de Pessoal de Nível Superior. Plataforma Sucupira. Brasília, DF: CAPES, c2016. Disponível em:

https://sucupira.capes.gov.br/sucupira/public/index. xhtml . Acesso em: 20 mar. 2020.

ENCITEC, Ensino de Ciências e Tecnologia em Revista. Sobre. Disponível em: http://srvapp2s.urisan.tche.br/seer/index.php/encitec. Acesso em 12 jan. 2021.

FAZENDA, Ivani. Dicionário em construção: interdisciplinaridade. São Paulo: Cortez, 2001.

FAZENDA, Ivani (Org.) O que é interdisciplinaridade? 2a ed. São Paulo, Cortez: 2013.

FRANÇA, Odila Amélia Veiga. Ação. In: FAZENDA, Ivani Catarina Arantes.

GODOY, Herminia Prado. Interdisciplinaridade: pensar, pesquisar, intervir. São Paulo: Cortez, 2014.

LAVAQUI, Vanderlei; BATISTA, Irinéa de Lourdes. Interdisciplinaridade em ensino de Ciências e de Matemática no Ensino Médio. Revista Ciências \& Educação. (Bauru), Bauru, v. 13, n. 3, p. 399-420, 2007. DOI: https://doi.org/10.1590/S151673132007000300009 .

LEITE, Denise et al. Avaliação de redes de pesquisa e colaboração. Revista da Avaliação da Educação Superior (Campinas), Sorocaba, v. 19, n. 1, p. 291-312, 2014. DOI: https://doi.org/10.1590/S1414-40772014000100014

LEMKE, Cláudia Elizandra; SCHEID, Neusa Maria John. O Ensino de Ciências e as Possibilidades de Interdisciplinaridade. In: BREMM, Daniele; MACIEL, Eloisa 
Antunes; ZISMANN, Jonatan Josias (org). Aprendendo Ciências: Pesquisa e PósGraduação-volume 3. Bagé-RS: Faith, 2019. p. 105-111.

LEMKE, Cláudia Elizandra; SCHEID, Neusa Maria John. As aproximações dos currículos de ciências e educação física. Brazilian Journal of Development, Curitiba, v. 6, n. 5, p.26393-26400, 2020. DOI: 10.34117/bjdv6n5-189.

MOZENA, Erika Regina; OSTERMANN, Fernanda. Uma revisão bibliográfica sobre a interdisciplinaridade no ensino das ciências da natureza. Ensaio Pesquisa em

Educação em Ciências (Belo Horizonte). Belo Horizonte, v. 16, n. 2, p. 185-206, 2014. DOI: https://doi.org/10.1590/1983-21172014160210.

PAVIANI, Jayme. Interdisciplinaridade: disfunções conceituais e enganos acadêmicos. Caxias do Sul: EDUCS, 1993.

PORLÁN, Rafael.; MARTÍN, José. EI diário del professor Um recurso para la investigacion em el aula. Editora Rocio Sur, 1991.

RADETZKE, Franciele Siqueira. O escrever reflexivo na constituição do Ser Professor. Revista Insignare Scientia - RIS, v. 1, n. 3, 2019. Disponível em: https://periodicos.uffs.edu.br/index.php/RIS/article/view/10600. Acesso em 21 jan. 2021.

RIEC, Red Internacional de Investigación en Enseñanza de las Ciencias. Página inicial do site. Disponível em: https://riec1.webnode.com/ . Acesso em 12 jan. 2021.

RIEC, Red Internacional de Investigación en Enseñanza de las Ciencias (nome de usuário). RIEC. Santo Ângelo, 19 jun. 2020. Facebook: Red Internacional de Investigación en Enseñanza de las Ciencias Facebook. Disponível em: https://www.facebook.com/permalink.php?story_fbid=121382579609296\&id=1135906 07055160. Acesso em 12 jan. 2021.

RIS, Revista Insignare Scientia. Sobre a revista. Disponível em: https://periodicos.uffs.edu.br/index.php/RIS?fbclid=IwAR3wHTb9nXLL_w7zQuM5zL 6F2USsprfOupfY4A4124Nw2WL55Wa3eY--Utw. Acesso em 12 jan. 2021.

SONNENWALD, Daine H. Scientific Collaboration: A Synthesis of Challenges and Strategies. Annual Review of Information Science and Technology, Blaise Cronin, (Ed,), Medford, NJ: Information Today, v.4, 2007. Disponível em: https://www.researchgate.net/publication/242081966_Scientific_Collaboration_A_Synt hesis_of_Challenges_and_Strategies/link/5d42d8c1a6fdcc370a71b426/download Acesso em 21 jan. 2021.

SOUZA, Marcela Tavares de; SILVA, Michelly Dias da; CARVALHO, Rachel de. Revisão integrativa: o que é e como fazer. Einstein (São Paulo), São Paulo, v. 8, n. 1, p. 102-106, Mar. 2010. Disponível em:

http://www.scielo.br/scielo.php?script=sci_arttext\&pid=S1679$45082010000100102 \& \operatorname{lng}=e n \& n r m=$ iso. Acesso em 12 jan. 2021. http://dx.doi.org/10.1590/s1679-45082010rw1134. 
TED, Tecné, Episteme y Didaxis. Sobre a revista. Disponível em:

https://revistas.pedagogica.edu.co/index.php/TED/about. Acesso em 12 jan. 2021.

TRIPP, David. Pesquisa-ação: uma introdução metodológica. Educação \& Pesquisa.

São Paulo, v. 31, n. 3, pág. 443-466, dezembro de 2005. Disponível em:

http://www.scielo.br/scielo.php?script=sci_arttext\&pid=S1517-

97022005000300009\&lng=en\&nrm=iso. Acesso em 12 de jan. 2021.

http://dx.doi.org/10.1590/S1517-97022005000300009.

UFFS, Universidade Federal da Fronteira Sul. Linhas de Pesquisa do Mestrado em

Ensino de Ciências. 2019 Disponível em: <https://www.uffs.edu.br/campi/cerrolargo/cursos/mestradocl/mestrado-em-ensino-de-ciencias/linhas-de-pesquisa $>$. Acesso em: 22 jan. 2021.

UNIJUÍ, Revista Contexto \& Educação. Sobre a revista. Disponível em:

https://www.revistas.unijui.edu.br/index.php/contextoeducacao/about. Acesso em 12 jan. 2021.

UNIMINUTO, Praxis Pedagógica. Sobre. Disponível em:

https://revistas.uniminuto.edu/index.php/praxis. Acesso em 12 jan. 2021.

ZABALZA, Miguel Angel. Diários de aula. Tradutores: José Augusto Pacheco e José Machado. Editora: Porto Editora. 1994.

ZEICHNER, Kenneth M. A formação reflexiva de professores: ideias e práticas. Lisboa: Educa Professores, 1993.

i Link do Vídeo de Lançamento da RIEC no canal do Youtube do CIECITEC:

https://www.youtube.com/watch?v=jqf23IhBXTQ\&feature=youtu.be. Acesso em: 21 dez. 2020.

Referências dos artigos utilizados na pesquisa:

R1: NEIRA, Marcela; HERNÁNDEZ, Análida. Construção de conhecimentos práticos, baseada na práxis de um professor na formação. Bio-grafia, v.5, n.8, p. 77-94, 2012.Disponível em:

https://revistas.pedagogica.edu.co/index.php/bio-grafia/article/view/1609 .Acesso em: 21 dez. 2020.

R2: LANES, Karoline G et al. O ensino de ciências e os temas transversais: práticas pedagógicas no contexto escolar. Revista Contexto \& Educação, v.29, n.92, p. 21-51. DOI: https://doi.org/10.21527/2179-1309.2014.92.21-51. Acesso em: 21 dez. 2020.

R3: SANTOS, Maria Cristina Ferreira dos; LAMEGO, Caio Roberto Siqueira; CRUZ, Nilza Joaquina Santiago da. Formação de professores e educação ambiental: uma abordagem interdisciplinar na construção de saberes e fazeres docentes na Biologia e Geografia. Bio-grafia, escritos sobre la Biología y su Enseñanza- Edição extraordinária. P. 993-1104, 2015. Disponível em:

https://revistas.pedagogica.edu.co/index.php/bio-grafia/article/view/3531 Acesso em: 21 dez. 2020.

R4: CUERVO BERNAL, M.; GUTIÉRREZ RODRÍGUEZ, A. Ecologia como prática educativa interdisciplinar entre educação física e tecnologia. Praxis Pedagógica, v. 16, n. 18, pág. 91-99,2016. Disponível em: https://revistas.uniminuto.edu/index.php/praxis/article/view/1369. Acesso em: $21 \mathrm{dez}$. 2020.

R5: CLEOPHAS, Maria das Graças; SANTOS, Emerson José Meira dos; FREIRE, Lhuan Junior Pinto. Construção de recursos didáticos para o empoderamento científico e ambiental das questões hídricas. 
Revista Tecné, Episteme y Didaxis: TED, Número Extraordinário, 2016. Disponível em: https://revistas.pedagogica.edu.co/index.php/TED/article/view/4719/3862. Acesso em: 21 dez. 2020.

R6: TORRES, Juliana Rezende et al. Ação da biologia PIBID na educação básica por meio da abordagem temática Freireano: ações formativas em Educação Ambiental. Bio-grafia, v. 10, n. 19, p.41-48,2017. Disponível em: https://revistas.pedagogica.edu.co/index.php/bio-grafia/article/view/7220. Acesso em: 21 dez. 2020.

R7: SCHEID, Neusa Maria John; SIQUEIRA, Ataiz Colvero de; PERSICH, Gracieli Dal Ostro. Contribuições da ferramenta KAHOOT! Na compreensão dos conceitos da área de ciências da natureza. Revista Tecné, Episteme y Didaxis, Número Extraordinário- Memorias, Octavo Congreso Internacional de formación de Profesores de Ciencias para la Construcción de Sociedades Sustentables, 2018. Disponível em:

https://revistas.pedagogica.edu.co/index.php/TED/article/view/9032/6784. Acesso em: 21 dez. 2020.

R8: ROCHA SOBREIRA, Elaine Silva; VIVEIRO, Alessandra Aparecida; VIEGAS D’ABREU, João Vilhete. Aprendizagem criativa na construção de jogos digitais: uma proposta educativa no ensino de ciências para crianças. Tecné, Episteme y Didaxis: TED, 44, 71-88, 2018. Disponível em: https://revistas.pedagogica.edu.co/index.php/TED/article/view/8990/6748 Acesso em: 21 dez. 2020.

R9: GRANDA, Jéssica Pimentel da Cunha et al. Uma experiência interdisciplinar: ensino de áreas e volumes utilizando o recurso computacional visualog. Revista Tecné, Episteme y Didaxis, Número Extraordinário- Memorias, Octavo Congreso Internacional de formación de Profesores de Ciencias para la Construcción de Sociedades Sustentables, 2018. Disponível em: https://revistas.pedagogica.edu.co/index.php/TED/article/view/9033/6785. Acesso em: 21 dez. 2020.

R10: CARLESSO, Janaína Pretto; TOLENTINO - NETOL, Luis Caldeira Brant de. As contribuições de um planejamento interdisciplinar com temáticas de ciências numa amostra de alunos com dificuldades de aprendizagem. Revista Contexto \& Educação, v. 33, n. 104, p. 129-150, 2018.Disponível em: https://www.revistas.unijui.edu.br/index.php/contextoeducacao/article/view/6725\#: :text=Acerca\%20diss o\%2C\%20observa\%2Dse\%20que,em\%20Matem\%C3\%A1 tica\%20e\%20L\%C3\%ADngua\%20Portuguesa . Acesso em: 21 dez. 2020.

R11: ECKERT, Giovana Laís. Experiências na formação inicial: primeiras interações com a sala de aula. Revista Insignare Scientia - RIS, v. 2, n. 3, p. 154-164, 2019. Disponível em: https://periodicos.uffs.edu.br/index.php/RIS/article/view/11194. Acesso em: 21 dez. 2020.

R12: LOPES DA CRUZ, Letiane. Desastre Ambiental do Exxon Valdez: temática de planejamento didático no ensino de Biologia. Revista Insignare Scientia - RIS, v. 2, n. 3, p. 202-206, 2019. Disponível em: https://periodicos.uffs.edu.br/index.php/RIS/article/view/11199. Acesso em: 21 dez. 2020.

R13: WUST, N. Minha primeira experiência como Professora de Biologia: desastres e esperanças. Revista Insignare Scientia - RIS, v. 2, n. 3, p. 214-221, 21 nov. 2019. Disponível em: https://periodicos.uffs.edu.br/index.php/RIS/article/view/11201. Acesso em: 21 dez. 2020.

R14: MORO, Fernanda Tereza; COPPI, Eliseu Pauli; PRSYBYCIEM, Moises Marques. Construção de um biodigestor: uma proposta de ensino interdisciplinar para escolas do campo. Revista Insignare Scientia - RIS, v. 2, n. 1, p. 104 - 115, 2019. Disponível em: https://periodicos.uffs.edu.br/index.php/RIS/article/view/10749. Acesso em: 21 dez. 2020.

R15: PEZZINI, Dalires Fátima. Trabalhando o conceito de densidade Educação Básica. Revista Insignare Scientia - RIS, v. 2, n. 3, p. 71-77, 2019. Disponível em: https://periodicos.uffs.edu.br/index.php/RIS/article/view/11181. Acesso em: 21 dez. 2020. 
R16: VISINTAINER, Daniela Sastre R..; SOARES, Félix Alexandre Antunes. O desenvolvimento de estratégias de ensino para a promoção da saúde na formação docente continuada. Revista Contexto \& Educação, v. 34, n. 109, p. 52-73, 2019. Disponível em:

https://www.revistas.unijui.edu.br/index.php/contextoeducacao/article/view/8615 Acesso em: $21 \mathrm{dez}$. 2020 .

R17: POMMER, Wagner Marcelo. As ações docentes em um projeto interdisciplinar nas aulas de ciências nos anos iniciais do ensino fundamental. Ensino de Ciências e Tecnologia em Revista, v. 9, n. 3, 2019. Disponível em: http://srvapp2s.santoangelo.uri.br/seer/index.php/encitec/article/view/871/pdf871. Acesso em: $21 \mathrm{dez} .2020$.

R18: SANTOS, Sandra Aparecida et al. A escrita e a leitura promovidas pela experimentação contextualizada e interdisciplinar na construção de conceitos científicos. Ensino de Ciências e Tecnologia em Revista, v. 9, n. 3, 2019. Disponível em: http://srvapp2s.santoangelo.uri.br/seer/index.php/encitec/article/view/3352. Acesso em: 21 dez. 2020.

R19: DUTRA, Raiane da Rosa; COUTINHO, Renato Xavier. Alimentação saudável e atividade física na escola através de uma abordagem contextualizada e interdisciplinar. Revista Contexto \& Educação, v. 35, n. 110, p. 123-141, 2020. Disponível em:

https://www.revistas.unijui.edu.br/index.php/contextoeducacao/article/view/8739. Acesso em: $21 \mathrm{dez}$. 2020.

R20: ARAÚJO, Amilson; SILVA, Ivanderson Pereira da; SERRA, Kleber Cavalcanti. Projeto engenharia de trânsito: robótica no semáforo de cruzamento. Ensino de Ciências e Tecnologia em Revista, v. 10, n.2, 2020. Disponível em: http://srvapp2s.santoangelo.uri.br/seer/index.php/encitec/article/view/2544. Acesso em: 21 dez. 2020.

R21: MOREIRA, Eveline da Silva Gontijo et al. O vídeo como recurso didático: uma intervenção pedagógica sobre o uso da água. Ensino de Ciências e Tecnologia em Revista, v. 10, n.2, 2020. Disponível em: http://srvapp2s.santoangelo.uri.br/seer/index.php/encitec/article/view/2827. Acesso em: 21 dez. 2020. 